RUNNING HEAD: GUILT PRONENESS AND CWB

\title{
Predicting Counterproductive Work Behavior from Guilt Proneness
}

\author{
Taya R. Cohen \\ Carnegie Mellon University \\ A. T. Panter \\ University of North Carolina at Chapel Hill \\ Nazli Turan \\ Carnegie Mellon University
}

Cohen, T. R., Panter, A. T., \& Turan, N. (2013). Predicting counterproductive work behavior from guilt proneness. Journal of Business Ethics, 114, 45-53. doi: 10.1007/s10551-012-1326-2. Available at: http://dx.doi.org/10.1007/s10551-012-1326-2

\section{Author Note}

This research was made possible through the support of the Tepper School of Business at Carnegie Mellon University and a grant by the Berkman Faculty Development Fund at Carnegie Mellon University. This paper was presented at the 2012 conference of the International Association for Conflict Management (IACM) in Cape Town, South Africa.

Address correspondence concerning this article to Taya R. Cohen, Carnegie Mellon University, Tepper School of Business, 5000 Forbes Avenue, Pittsburgh, PA 15213. Email: tcohen@cmu.edu. Phone: (412) 268-6677. 


\begin{abstract}
We investigated the relationship between guilt proneness and counterproductive work behavior (CWB) using a diverse sample of employed adults working in a variety of different industries at various levels in their organizations. CWB refers to behaviors that harm or are intended to harm organizations or people in organizations. Guilt proneness is a personality trait characterized by a predisposition to experience negative feelings about personal wrongdoing. CWB was engaged in less frequently by individuals high in guilt proneness compared to those low in guilt proneness, controlling for other known correlates of CWB. CWB was also predicted by gender, age, intention to turnover, interpersonal conflict at work, and negative affect at work. Given the detrimental impact of CWB on people and organizations, it may be wise for employers to consider guilt proneness when making hiring decisions.
\end{abstract}

Keywords: Counterproductive work behavior; guilt proneness; unethical behavior; morality; personality; individual differences; 


\section{Predicting Counterproductive Work Behavior from Guilt Proneness}

Counterproductive work behavior (CWB) is volitional behavior that harms or intends to harm organizations or people in organizations (Fox \& Spector, 2005; Spector, 2011; Spector, Bauer, \& Fox, 2010; Spector, Fox, Penney, Bruursema, Goh, \& Kessler, 2006). The categories of behavior that comprise CWB are: abuse toward others (e.g., starting or continuing a damaging or harmful rumor at work; being nasty or rude to a client or customer); production deviance (e.g., purposely doing your work incorrectly; purposely working slowly when things need to get done); sabotage (e.g., purposely wasting your employer's materials/supplies; purposely damaging a piece of equipment or property); theft (e.g., stealing something belonging to your employer; putting in to be paid for more hours than you work); and withdrawal (e.g., coming to work late without permission; staying home from work and saying you were sick when you weren't). These are behaviors that are generally regarded as unethical and a threat to the well-being of organizations and their members.

Although CWB is comprised of five categories (Spector et al., 2006), most research that assesses the construct uses total sum scores rather than subscale scores (e.g., Dalal, 2005; Fox et al., 2011; Spector et al., 2010; Zettler \& Hilbig, 2010). Thus, CWB is an aggregated set of behaviors, rather than a single type behavior. Aggregated behaviors are more consistent across time and situations compared to single behaviors, and they can be predicted more reliably by personality and situational variables (Fleeson \& Noftle, 2009; Funder, 2008).

CWB can be assessed with both self-reports and observer-reports (e.g., reports by coworkers or managers); however, a recent meta-analysis (Berry, Carpenter, \& Barratt, 2012) found that self-reports provide more reliable and valid assessments of CWB than observerreports. Self- and other-ratings of CWB do tend to be highly correlated, but observer-ratings 
under-report the frequency of CWB, likely because counterproductive behaviors are intended by the perpetrators to be unobservable (Berry et al., 2012; Dalal, 2005; Spector \& Fox, 2005). Put simply, individuals have more information about their own behaviors than do observers. Thus, although observer-reports may be less subject to socially-desirable responding, they necessarily rely on a source with incomplete information about the target's behavior-only the target knows what counterproductive acts she or he has performed. Accordingly, Berry et al. (2012) recommend assessing CWB with self-reports and taking steps to assure respondents of their anonymity, for example by having them complete CWB assessments online, where they feel a sense of privacy.

Spector and Fox (2005) reviewed the predictors of CWB and concluded that it is determined by both individual differences and situational factors (see also Berry et al., 2012; Spector, 2011). For example, CWB is predicted by job satisfaction and job stressors, as well as negative emotions; it has an inconsistent relationship with positive emotions (Spector \& Fox, 2005). Interpersonal conflict at work - the degree to which people get into arguments and are treated poorly at their job (Spector \& Jex, 1998)—is among the most frequently reported job stressors (Keenan \& Newton, 1985) and is one of the strongest known predictors of CWB (Fox et al., 2011; Spector et al., 2006; Spector et al., 2010).

Some researchers argue that CWB and unethical behavior are distinct constructs, with CWB being a violation of organizational norms and unethical behavior a violation of societal norms (Kish-Gephart, Harrison, \& Trevino, 2010). However, in most circumstances harming others is considered a moral violation (Graham, Nosek, Haidt, Iyer, Koleva, \& Ditto, 2011; Haidt, 2007; Rai \& Fiske, 2011). Given that harm is integral to the definition of CWB, it may be helpful to view CWB through the lens of unethical behavior. One reason is because viewing 
CWB as unethical behavior allows for the prediction that personality and situational factors that affect unethical behavior will also affect CWB. One such factor is guilt proneness.

Guilt proneness is an individual difference reflecting a predisposition to experience negative feelings about personal wrongdoing, even when the wrongdoing is private (Cohen, Wolf, Panter, \& Insko, 2011; Tangney \& Dearing, 2002; Tangney, Stuewig, \& Mashek, 2007; Tangney, Youmam, \& Stuewig, 2009; Wolf, Cohen, Panter, \& Insko, 2010). It is an emotional trait, referring to the anticipation of feeling guilty about committing transgressions, rather than a specific emotional state characterized by guilty feelings in a particular moment or generalized guilty feelings that occur without an eliciting event.

Guilt proneness can be reliably measured with the Guilt and Shame Proneness scale (GASP; Cohen et al., 2011). In the guilt proneness subscale of the GASP (i.e., Guilt-NegativeBehavior-Evaluation), respondents are asked to imagine that they have committed a transgression that no one knows about (e.g., you secretly commit a felony), and then indicate the likelihood that they would feel badly about their behavior (e.g., you would feel remorse about breaking the law). Our recent research with the GASP finds that guilt proneness is a temporally stable trait among American adults (Cohen, Panter, Turan, \& Morse, 2012). For example, in September 2011, we administered the GASP to 1,032 employed adults from across the U.S. (ages 18-71, 48\% women). Thirteen weeks later we re-contacted these individuals and asked them to complete a follow-up survey; $53 \%$ of them responded $(N=548)$. We found a test-retest correlation of $.69(p<.001)$ indicating that guilt proneness, as measured by the GASP, is a highly reliable individual difference.

Prior studies of guilt proneness indicate that it is an important character trait that predicts the likelihood that people will engage in unethical behavior (Cohen et al., 2011; Tangney et al., 
2007; Tangney, Youman, \& Stuewig, 2009). Why should guilt proneness predict unethical behavior? The anticipation of guilty feelings about private misdeeds in itself indicates that one has internalized moral values. Thus, for guilt-prone individuals public surveillance should not be required to prevent moral transgressions; instead, their conscience should guide them in their decision making. Evidence of guilt proneness as a character trait comes from several studies reported by Cohen et al. (2011). They found that people who scored high in guilt proneness (compared to low scorers) made fewer unethical business decisions, committed fewer delinquent behaviors (at work and outside of work), and behaved more honestly when they made economic decisions (Cohen et al., 2011, Study 2). Moreover, Masters of Business Administration (MBA) students high in guilt proneness were judged by their classmates as being more honest negotiators than those low in guilt proneness (Cohen et al., 2011, Study 3). The negotiation study provided particularly compelling evidence of guilt proneness as a character trait as guilt proneness was assessed one to four weeks prior to the negotiation and honesty was judged by the negotiation counterparts following an exercise in which the students had opportunities to lie. In addition to these behavioral findings, cross-sectional surveys with the GASP have consistently found that guilt proneness is positively correlated with other moral personality measures, including honesty-humility, moral identity, moral idealism/relativism, conventional morality, consideration of future consequences, empathic concern, and perspective taking (Cohen et al., 2011, 2012; see also Tangney et al., 2007, 2009). Overall, these findings suggest that guilt proneness predisposes people to think, feel, and act in morally-relevant ways.

Whereas the extant research reviewed above suggests that the GASP has the potential to be an important measurement tool for detecting individuals who are chronically susceptible to unethical behavior, we do not yet know whether the scale can be used to predict people's 
counterproductive behaviors at work. The workplace is an important setting to study character and behavior because most adults spend a substantial portion of their lives at work (U.S. Bureau of Labor Statistics, 2010b). However, there are few studies examining guilt proneness in organizational settings. One exception is a study by Flynn and Schaumberg (2011). They found that highly guilt-prone employees work harder at their jobs (i.e., they expend more effort at work), and this effort is associated with increases in affective organizational commitment. The current research extends this work by testing whether low guilt proneness is an antecedent of CWB. We hypothesized that employees high in guilt proneness would commit fewer counterproductive work behaviors than employees low in guilt proneness, and that this relationship would hold after controlling for other known correlates of CWB.

\section{Method}

We recruited 443 American adults with full-time employment (working 35 hours or more per week) from Amazon's Mechanical Turk (MTurk) website to complete a 15-minute “Workplace Behavior Study”. Consistent with typical MTurk payment rates (Buhrmester, Kwang, \& Gosling, 2011), each participant who completed the study was paid $\$ 0.50$. The survey was launched on June 13, 2011 and all responses were completed by June 17, 2011. To encourage honest responding, we administered the survey online and presented participants with the following information at the beginning:

Please keep in mind that all information collected in this survey is kept completely confidential and secure, and only the research team will have access to the data. After the data are collected, all personally identifiable information will be removed and translated to an anonymous participant id code. We appreciate your honest and candid responses. 


\section{Procedure}

The survey began by asking participants about their job and the organization for which they worked. They were informed that they would be asked questions about their experiences at their job during the past week (i.e., the previous seven days). If they had multiple jobs, they were instructed to answer the questions based on their primary source of employment (the job that they work at the most). We surveyed people about the past week at work because we reasoned that the time period was short enough where people could accurately remember and report on their behaviors, but long enough for instances of CWB to occur.

After describing their job and organization, participants responded to a variety of questionnaires. The order of the questionnaires and the items within each questionnaire were randomized for each participant. For the questionnaires about work situations and behaviors, we included a "not applicable" response option in case certain situations and behaviors were not relevant to the respondent's employment situation. We coded not applicable responses as missing data. The survey ended with a section in which the participant reported demographic information. The survey ended with a short section assessing demographic characteristics.

The study included assessments of guilt proneness and CWB committed during the past week at work. In addition, on the basis of Spector and Fox's (2005) review of the correlates of CWB, we included the following control variables in our study: interpersonal conflict during the past week at work, negative affect during the past week at work, positive affect during the past week at work, job satisfaction, and intention to turnover within the next year. We also included the number of hours worked during the past week, with the idea that the more hours worked, the more opportunities to commit CWB. Gender and age were also included as covariates because prior research has found that these demographic characteristics are associated with guilt 
proneness (Cohen et al., 2011) and unethical behavior (Kish-Gephart et al., 2010). Finally, we included tenure with the organization (in months) as a control variable because guilt proneness has been shown to correlate with organizational commitment (Schaumberg \& Flynn); we reasoned that guilt prone employees might have a longer tenure in the organization, which could influence their CWB. ${ }^{1}$

\section{Measures}

Job variables. Included in the initial job-information section were questions about tenure at the job ("When did you begin working in your current position), and hours worked during the past week ("How many hours did you work at your job during the past week?"), as well as questions about income and the industry in which the respondent worked. The job-information section also assessed intentions to turnover and job satisfaction, which were measured with items developed by Cammann, Fichman, Jenkins, and Klesh (1983). Intention to turnover was measured with the item, "How likely is that you will actively look for a new job in the next year? $(1=$ not at all likely, $7=$ extremely likely $)$. Job satisfaction was measured with three items $(\alpha=$ .90), which we modified to refer to the past week (e.g., "During the past week, I liked working at my job”). Responses options ranged from strongly disagree (1) to strongly agree (7).

Guilt proneness. Each participant completed the GASP (Cohen et al., 2011), which includes a four-item guilt-proneness subscale $(\alpha=.73)$. Participants were instructed to imagine themselves in a variety of situations that people are likely to encounter in day-to-day life and indicate the likelihood that they would react in the way described $(1=$ very unlikely, $2=$ unlikely, 3 = slightly unlikely, $4=$ about $50 \%$ likely, $5=$ slightly likely, $6=$ likely, $7=$ very likely). The guilt-proneness items described private transgressions and respondents indicated the likelihood that they would feel badly about their behavior. The items were: (1) After realizing 
you have received too much change at a store, you decide to keep it because the salesclerk doesn't notice. What is the likelihood that you would feel uncomfortable about keeping the money?; (2) You secretly commit a felony. What is the likelihood that you would feel remorse about breaking the law?; (3) At a coworker's housewarming party, you spill red wine on their new cream-colored carpet. You cover the stain with a chair so that nobody notices your mess. What is the likelihood that you would feel that the way you acted was pathetic?; (4) You lie to people but they never find out about it. What is the likelihood that you would feel terrible about the lies you told?

Counterproductive work behavior checklist (CWB-C). We assessed CWB with the 32-item Counterproductive Work Behavior Checklist (CWB-C; Spector et al., 2006; scale available at http://shell.cas.usf.edu/ pspector/scales/cwbcpage.html). ${ }^{2}$ We modified the instructions and response format to refer to past week at work. Participants were instructed to "indicate how often you did each of the following things at your job during the past week" using a five-point scale $(0=$ not at all this week; $1=$ one time this week; $2=$ two times this week; $3=$ three times this week; 4 = four or more times this week). The 32 items in the CWB-C were found to be internally consistent $(\alpha=.97) .^{3}$

Interpersonal conflict at work (ICAWS). Participants indicated their interpersonal conflict at work with the four-item Interpersonal Conflict at Work Scale (ICAWS; Spector \& Jex, 1998; scale available at http://shell.cas.usf.edu/ pspector/scales/strspage.html). We changed the instructions and response format to refer to the past week at work $(\alpha=.83)$. Participants were instructed to "indicate how often each of the following things happened to you at your job during the past week" using a 5-point scale $(0=$ not at all this week; $1=$ one time this week; $2=$ two times this week; 3 = three times this week; $4=$ four or more times this week). Sample items 
include, "You got into an argument with someone" and "Other people did nasty things to you."

Positive and Negative Affect Schedule (PANAS). We assessed negative and positive affect with the PANAS (Watson, Clark, Tellegen, 1998). Participants were instructed to indicate the extent to which they experienced 10 positive and 10 negative emotions at their job during the past week. Response options ranged from 1 (not at all) to 5 (extremely). Sample items for positive affect included active, determined, attentive and excited. The ten positive affect items were found to be internally consistent $(\alpha=.93)$. Sample items for negative affect included afraid, nervous, hostile and jittery. These ten items were also internally consistent $(\alpha=.92)$.

\section{Participants}

Demographic information about the sample. Participants lived in 45 U.S. states, and three reported being American but living outside the U.S. The sample contained 55.6\% women $(44.4 \%$ men) and the average age was 31.23 years $(S D=10.77 ;$ Range $=18-79)$. The racial/ethnic composition of the sample was $75.7 \%$ White, $6.8 \%$ Asian, $7.2 \%$ Black, $4.9 \%$ Hispanic/Latino, and 5.4\% "other" (the "other" category included respondents who did not selfidentify with one of these categories, as well as respondents who reported multiple ethnicities). With regard to education, $10.1 \%$ of the respondents had a high school education or less; $28.1 \%$ completed some college (no degree); $11.7 \%$ had a two-year degree (e.g., Associate's); 34.0\% had a four-year degree (e.g., Bachelor's); $12.4 \%$ had a Master's degree; and 3.7\% had a doctoral or professional degree.

Employment information about the sample. Participants reported working an average of 40.86 hours during the past week $(S D=9.34$, Range $=0$ to 80$)$. They worked in a variety of occupations, in both the private and public sectors. Specifically, $64.6 \%$ were employees in private for-profit companies or businesses; $11.7 \%$ were employees in private not-for-profit, tax- 
exempt, or charitable organizations; $17.4 \%$ were government employees; and $6.3 \%$ were selfemployed. Participants' tenure at their current job varied from less than one month to over 34 years $(M=46.91$ months, $S D=61.69$ months; Median $=24.75$ months; Range $=0.10$ to 408.27 months). Yearly income also varied widely, ranging from $\$ 0$ for volunteer work to $\$ 450,000$ for owning and operating a small business $(M=\$ 38,811, S D=\$ 33,140 ;$ Median $=\$ 33,000)$.

Participants self-reported their occupational classification using the 23 Standard Occupational Classification codes from the U.S. Bureau of Labor Statistics (2010a). We instructed participants to "Please choose the occupational category that best describes your current job. If your occupation is not in the main list, mark "other" and fill in your occupation." Nearly ninety percent of respondents $(88.0 \%)$ classified themselves into a category, with remainder choosing "other." Of the 23 potential categories, 22 were represented in the sample (the only category not selected was "Farming, Fishing, and Forestry Occupations").

\section{Results}

Fifteen participants left the study before completing it and several other participants had missing data on some items. Because of these missing responses, the sample size varied from 411 to 434 depending on the analysis.

To test our predictions concerning CWB, we determined the factor structure of each scale using confirmatory factor analysis, computed factor scores, and conducted regression analyses using the factor scores. This approach allowed us to account for missing data while also employing WLSMV estimation (mean and variance adjusted weighted least squares) to accommodate the ordered-categorical nature of the items (Stucky, Gottfredson, \& Panter, 2012; Wirth \& Edwards, 2007). It was particularly important to use an analytic approach that could account for missing data because $17 \%$ of the respondents indicated that one or more of the CWB 
items were not applicable to them.

The confirmatory factor analyses were conducted using Mplus 6 (Muthén \& Muthén, 1998-2010) with all available data. The models used WLSMV estimation and factor variances were fixed to 1 to set the scale of the latent variables. We assessed model fit with chi-square $\left(\chi^{2}\right)$, Root Mean Square Error of Approximation (RMSEA), Comparative Fit Index (CFI), and Tucker Lewis Index $(T L I)$. Good-fitting models meet some or all of the following criteria: nonsignificant chi-square, RMSEA <.06, CFI > .95, and TLI> .95 (Hu \& Bentler, 1999; Yu, 2002). Degrees of freedom $(d f)$ vary for the chi-square tests because they are calculated differently with WLSMV estimation than traditional estimation methods (Muthén \& Muthén, 1998-2010). Because of the variation in the degrees of freedom, we report the number of estimated (i.e., free) parameters in each model.

\section{Factor Analytic Results}

A one-factor model of the CWB-C showed excellent fit and all 32 items loaded highly on the factor $(\lambda \mathrm{s}>|.68|, p s<.001) ; \chi^{2}($ estimated parameters $=160, d f=464, N=420)=510.94, p=$ $.065 ; R M S E A=.016 ; C F I=1.00 ; T L I=1.00$. These results support our decision to treat $\mathrm{CWB}$ as an aggregated set of behaviors. ${ }^{4}$

As in prior research with the GASP (Cohen et al., 2011), the guilt proneness scale had a unidimensional structure and all four items loaded highly on the factor $(\lambda s>|.62|, p s<.001)$; $\chi^{2}($ estimated parameters $=28, d f=2, N=434)=9.66, p=.008 ; R M S E A=.094 ; C F I=.99 ; T L I$ $=.97$.

The interpersonal conflict at work scale also had a unidimensional structure and all four items loaded highly on the factor $(\lambda \mathrm{s}>|.75|, p \mathrm{~s}<.001) ; \chi^{2}($ estimated parameters $=20, d f=2, N$ $=423)=6.53, p=.038 ; R M S E A=.073 ; C F I=1.00 ; T L I=.99$. 
The PANAS was best modeled by a two-factor structure, with the ten negative affect items loading highly on a negative affect factor $(\lambda s>|.74|, p s<.001)$ and the ten positive items loading highly on a positive affect factor $(\lambda \mathrm{s}>|.76|, p \mathrm{~s}<.001) ; \chi^{2}($ estimated parameters $=101$, $d f=169, N=435)=866.84, p<.001 ; R M S E A=.097 ; C F I=.94 ; T L I=.94$.

Because the job satisfaction scale only contained three items, there were no degrees of freedom to compute model fit statistics; nonetheless, all three items loaded highly on the factor $(\lambda \mathrm{s}>|.83|, p s<.001$, and we were able to compute a factor score for job satisfaction.

\section{Regression Results}

The regression analysis contained 411 participants for whom we could compute factor scores for all the variables of interest. Table 1 shows the means, standard deviations, and bivariate correlations among the variables. ${ }^{5}$ Table 2 shows the regression results. Age, hours worked during the past week, tenure at job, and intention to turnover were each mean-centered prior to computing the regression analysis.

The control variables (gender, age, hours worked during the past week, tenure at job, job satisfaction, intention to turnover within a year, interpersonal conflict at work, negative affect and positive affect) were entered in Step 1 of the regression analysis. Guilt proneness was entered in Step 2.

Overall, the employment and demographic variables entered in Step 1 of the regression analysis accounted for $39 \%$ of the variance in CWB. As shown in Table 2, Step 1 of the analysis revealed significant effects of gender, age, intention to turnover, interpersonal conflict at work and negative affect at work. Women and older participants committed fewer counterproductive work behaviors compared to men and younger participants, respectively. In addition, participants with higher intention to turnover within a year committed more CWB than those with lower 
intentions to turnover. Participants reporting higher interpersonal conflict also committed more CWB than those reporting lower interpersonal conflict. Similarly, participants reporting higher negative affect at work committed more CWB than those that reported lower negative affect. Job satisfaction also marginally predicted CWB in that participants reporting higher job satisfaction committed somewhat more CWB than those reporting less job satisfaction. Hours worked in the past week, tenure at job and positive affect were not significant predictors of CWB.

We entered guilt proneness in Step 2 of the regression analysis and consistent with predictions, we found a significant effect. Participants who reported being more guilt-prone committed fewer counterproductive work behaviors than participants who reported being less guilt-prone. Moreover, the bivariate correlation between guilt-proneness and CWB was significant, $r=-.33, p<.001$.

\section{Discussion}

Our results suggest that CWB is predicted by gender, age, intention to turnover, interpersonal conflict at work, negative affect at work, and guilt proneness. We are not suggesting that the variables included in this study are the only variables relevant to predicting harmful and/or unethical behavior at the workplace. There are, of course, other known correlates of CWB, such as honesty-humility (Marcus, Lee, \& Ashton, 2007; Zettler \& Hilbig, 2010), trait anger and anxiety (Spector \& Fox, 2005), organizational constraints (Fox et al., 2011; Spector \& Fox, 2005; Spector et al., 2010) and organizational politics (Zettler \& Hilbig, 2010). ${ }^{6}$ Instead, our goal with this paper was to extend the CWB literature to include a predisposition to feel guilt over wrongdoing. We provided evidence of this relationship using a diverse sample of employed adults who worked in many different industries at various levels in their organizations and controlled for a host of other known correlates of CWB. 
A limitation of the current study is that we relied exclusively on self-reported personality, work setting information, and CWB. Given that CWB is generally considered unethical and intended to be unobservable, self-reports might be influenced by socially-desirable responding. We attempted to circumvent the potential for biased responding by using an online survey and assuring respondents that the information they provided was confidential and anonymous. However, even with anonymous responding, participants may still desire to appear moral to themselves and engage in self-deception (Chance, Norton, Gino, \& Ariely, 2011). An alternative approach would have been to use observer-reports of CWB, but as discussed in the introduction, observer-reports of CWB have been found to be less valid than self-reports (Berry et al., 2012). Thus, neither self-reports nor observer-reports are free from methodological limitations. Accordingly, there is precedent for measuring CWB in both formats. We find it reassuring that self and observer ratings of CWB tend to be positively correlated and correlate similarly with theoretically-related variables (Berry et al., 2012; Dalal, 2005; Fox et al., 2011; Spector et al., 2010; Spector \& Fox, 2005). Nonetheless, in future research we plan to assess CWB and guilt proneness with self-reports and co-worker-reports to replicate conceptually the current findings and test whether self-reports or observer-reports of guilt proneness are better predictors of CWB and other unethical behaviors.

A second study limitation is its cross-sectional design. We only assessed each construct at one time point. Longitudinal designs in which personality, situations, and behaviors can be assessed at multiple times points yield more reliable findings than cross-sectional designs that assess these constructs at a single point in time (Hampson, 2011; Nesselroade, 2007). In future research we plan to use a weekly online diary method (Bolger, Davis, \& Rafaeli, 2003; Iida, Shrout, Laurenceau, \& Bolger, 2012) to assess interpersonal conflict at work and CWB at 
multiple time points. This measurement technique would allow for more reliable assessments of workplace situations and behaviors.

\section{Conclusions}

The correlation between guilt proneness and CWB was found to be -.33 . Is this a small or large effect? To answer this question, assume a company hired 100 employees, half of whom were high in guilt proneness, half of whom were low. Using the binomial effect size formula (Rosenthal \& Rubin, 1982; see also Funder and Fast, 2010), $50+(r / 2 \times 100)$, we can estimate that 66 of the employees low in guilt proneness would engage in CWB frequently whereas only 34 of the employees high in guilt proneness would engage in CWB frequently. Given the detrimental impact of CWB on people and organizations, it may be wise for employers to consider guilt proneness when making hiring decisions. We caution that this recommendation is preliminary, as the GASP scale has yet to be psychometrically normed for personnel selection purposes. 


\section{References}

Berry, C. M., Carpenter, N. C., \& Barratt, C. L. (2012). Do other-reports of counterproductive work behavior provide an incremental contribution over self-reports? A meta-analytic comparison. Journal of Applied Psychology. doi: 10.1037/a0026739

Bolger, N., Davis, A., \& Rafaeli, E. (2003). Diary methods: Capturing life as it is lived. Annual Review of Psychology, 54, 579-617. doi: 10.1146/annurev.psych

Bollen, K., \& Lennox, R. (1991). Conventional wisdom on measurement: A structural equation perspective. Psychological Bulletin, 110, 305-314.

Buhrmester, M., Kwang, T., \& Gosling, S. D. (2011). Amazon's Mechanical Turk: A new source of inexpensive, yet high-quality, data? Perspectives on Psychological Science, 6(1), 3-5. doi: $10.1177 / 1745691610393980$

Cammann, C., Fichman, M., Jenkins, G. D., \& Klesh, J. R. (1983). Assessing the attitudes and perceptions of organizational members. In S. E. Seashore, E. E. Lawler, P. H. Mirvis \& C. Cammann (Eds.), Assessing organizational change: A guide to methods, measures, and practices (pp. 71-138). New York: John Wiley.

Chance, Z., Norton, M. I., Gino, F., \& Ariely, D. (2011). Temporal view of the costs and benefits of self-deception. Proceedings of the National Academy of Sciences. doi: 10.1073/pnas. 1010658108

Cohen, T. R., Panter, A. T., Turan, N., Morse, L. A. (2012). The WECT Project: Workplace experiences and character traits [project information]. Retrieved from http://WECTProject.org

Cohen, T. R., Wolf, S. T., Panter, A. T., \& Insko, C. A. (2011). Introducing the GASP scale: A new measure of guilt and shame proneness. Journal of Personality and Social 
Psychology, 100(5), 947-966. doi: 10.1037/a0022641

Dalal, R. S. (2005). A meta-analysis of the relationship between organizational citizenship behavior and counterproductive work behavior. Journal of Applied Psychology, 90(6), 1241-1255. doi: 10.1037/0021-9010.90.6.1241

Edwards, J. R., \& Bagozzi, R. P. (2000). On the nature and direction of relationships between constructs and measures. Psychological Methods, 5, 155-174.

Fleeson, W., \& Noftle, E. E. (2009). In favor of the synthetic resolution to the person-situation debate. Journal of Research in Personality, 43(2), 150-154.

Flynn, F. J., \& Schaumberg, R. L. (2011). When feeling bad leads to feeling good: Guiltproneness and affective organizational commitment. Journal of Applied Psychology. doi: $10.1037 / \mathrm{a} 0024166$

Fox, S., \& Spector, P. E. (Eds.). (2005). Counterproductive work behavior: Investigations of actors and targets. Washington, DC: American Psychological Association.

Funder, D.C. (2008). Persons, situations and person-situation interactions. In O.P. John, R. Robins \& L. Pervin (Eds.), Handbook of Personality (3rd Ed., pp. 568-580. New York: Guilford.

Graham, J., Nosek, B. A., Haidt, J., Iyer, R., Koleva, S., \& Ditto, P. H. (2011). Mapping the moral domain. Journal of Personality and Social Psychology, 101(2), 366-385. doi: $10.1037 / \mathrm{a} 0021847$

Haidt, J. (2007). The new synthesis in moral psychology. Science, 316(5827), 998-998.

Hampson, S. E. (2011). Personality processes: Mechanisms by which personality traits "get outside the skin" Annual Review of Psychology. doi: 10.1146/annurev-psych-120710100419 
Iida, M., Shrout, P. E., Laurenceau, J.-P., \& Bolger, N. (2012). Using diary methods in psychological research. In H. Cooper, P. Camic, D. Long, A. T. Panter, D. Rindskopf \& K. Sher (Eds.), APA handbook of research methodology in psychology (3 volumes). Washington, DC: APA Books.

Keenan, A., \& Newton, T. J. (1985). Stressful events, stressors, and psychological strains in young professional engineers. Journal of Occupational Behavior, 6, 151-156.

Kish-Gephart, J. J., Harrison, D. A., \& Treviño, L. K. (2010). Bad apples, bad cases, and bad barrels: Meta-analytic evidence about sources of unethical decisions at work. Journal of Applied Psychology, 95(1), 1-31. doi: 10.1037/a0017103

Marcus, B., Lee, K., \& Ashton, M. C. (2007). Personality dimensions explaining relationships between integrity tests and counterproductive behavior: Big five, or one in addition? Personnel Psychology, 60(1), 1-34.

McCrae, R. R., Kurtz, J. E., Yamagata, S., \& Terracciano, A. (2011). Internal consistency, retest reliability, and their implications for personality scale validity. Personality and Social Psychology Review, 15(1), 28-50. doi: 10.1177/1088868310366253

Muthén, L. K., \& Muthén, B. O. (1998-2010). Mplus User’s Guide (Sixth Edition). Los Angeles, CA.

Nesselroade, J. R. (2007). Factoring at the individual level: Some matters for the second century of factor analysis. In R. Cudeck \& R. C. MacCallum (Eds.), Factor analysis at 100: Historical developments and future directions (pp. 249-264).Mahwah, NJ: Erlbaum.

Rai, T. S., \& Fiske, A. P. (2011). Moral psychology is relationship regulation: Moral motives for unity, hierarchy, equality, and proportionality. Psychological Review, 118(1), 57-75. doi: $10.1037 / \mathrm{a} 0021867$ 
Schmitt, N. (1996). Uses and abuses of coefficient alpha. Psychological Assessment, 8(4), 350353.

Spector, P. (2011). The relationship of personality to counterproductive work behavior (CWB): An integration of perspectives. Human Resource Management Review, 21, 342-352.

Spector, P. E., Bauer, J. A., \& Fox, S. (2010). Measurement artifacts in the assessment of counterproductive work behavior and organizational citizenship behavior: Do we know what we think we know? Journal of Applied Psychology, 95(4), 781-790. doi: $10.1037 / \mathrm{a} 0019477$

Spector, P. E., Fox, S., Penney, L., Bruursema, K., Goh, A., \& Kessler, S. (2006). The dimensionality of counterproductivity: Are all counterproductive behaviors created equal? Journal of Vocational Behavior, 68(3), 446-460. doi: 10.1016/j.jvb.2005.10.005

Spector, P. E., \& Jex, S. M. (1998). Development of four self-report measures of job stressors and strain: Interpersonal Conflict at Work Scale, Organizational Constraints Scale, Quantitative Workload Inventory, and Physical Symptoms Inventory. Journal of Occupational Health Psychology, 3, 356-367.

Stucky, B., Gottfredson, N. C., \& Panter, A. T. (2012). Item factor analysis. In H. Cooper, P. Camic, D. Long, A. T. Panter, D. Rindskopf, D., \& K. Sher (Eds.). APA handbook of research methodology in psychology (three volumes). Washington, DC: APA Books.

Tangney, J. P., \& Dearing, R. L. (2002). Shame and guilt. New York: Guilford Press.

Tangney, J. P., Stuewig, J., \& Mashek, D. J. (2007). Moral emotions and moral behavior. Annual Review of Psychology, 58, 345-372. 
Tangney, J. P., Youman, K., \& Stuewig, J. (2009). Proneness to shame and proneness to guilt. In M. R. Leary \& R. H. Hoyle (Eds.), Handbook of individual differences in social behavior (pp. 192-209). New York: Guilford.

U.S. Bureau of Labor Statistics (2010a). 2010 Standard Occupational Classification (SOC User Guide). Available from: http://www.bls.gov/soc/\#materials

U.S. Bureau of Labor Statistics (2010b). American time use survey. Available from: http://www.bls.gov/news.release/atus.nr0.htm.

Watson, D., Clark, L.A. \& Tellegen, A. (1988). Development and validation of brief measures of positive and negative affect: The PANAS scales. Journal of Personality and Social Psychology, 54, 1063-1070.

Wirth, R. J., \& Edwards, M. C. (2007). Item factor analysis: Current approaches and future directions. Psychological Methods, 12(1), 58-79. doi: 10.1037/1082-989X.12.1.58

Wolf, S. T., Cohen, T. R., Panter, A. T., \& Insko, C. A. (2010). Shame proneness and guilt proneness: Toward the further understanding of reactions to public and private transgressions. Self \& Identity, 9(4), 337-362. doi: 10.1080/15298860903106843

Yu, C.-Y. (2002). Evaluating cutoff criteria of model fit indices for latent variable models with binary and continuous outcomes. Doctoral Disseration, University of California, Los Angeles.

Zettler, I., \& Hilbig, B. E. (2010). Honesty-Humility and a person-situation interaction at work. European Journal of Personality, 24, 569-582. 


\section{Footnotes}

${ }^{1}$ In addition, the survey also included assessments of organizational citizenship behavior (OCB) and morality judgments of counterproductive and citizenship behaviors. Because those scales are not relevant to the current study, we do not discuss them further. Information about these measures are available from the authors upon request.

${ }^{2}$ The CWB-C items were embedded in a longer list of items that also included 20 organizational citizenship behavior (OCB) items (Fox et al., 2011) interspersed with the 32 CWB items. Because our research question concerned CWB rather than OCB, we do not discuss the OCB findings further (however, information is available from the authors upon request).

${ }^{3}$ Although the alpha level of .97 was particularly high, it is consistent with prior research using the CWB-C, which generally finds alpha levels of .90 or higher for the longer (45-item) CWB-C (see Paul Spector's website for psychometric information about the scale: http://shell.cas.usf.edu/ pspector/scales/cwbcover.html). The authors of the CWB-C point out that the measure is behavior checklist (i.e., a causal indicator scale) containing items that are not parallel assessments of a single underlying construct (Spector et al., 2006). For this type of measure, internal consistency is not a good indicator of reliability (Bollen \& Lennox, 1991; Edwards \& Bagozzi, 2000). For further discussion of the limitations of internal consistency as an indicator of reliability, see McCrae, Kurtz, Yamagata, \& Terracciano 2011; Schmitt, 1996.

${ }^{4}$ Although the one-factor model had excellent fit, we also attempted to estimate a five-factor model of the CWB-C; however, factor scores could not be computed because the latent variable covariance matrix was not positive definite. 
${ }^{5}$ In addition to analyzing total CWB-C scores, we analyzed each of the five CWB-C subscales separately (calculated as sum scores, rather than factor scores). The guilt proneness factor was significantly negatively correlated with each of the five subscales, ranging from $r(389)=-.28, p<.001$ for production deviance, to $r(389)=-.22, p<.001$ for theft.

${ }^{6}$ Although Conscientiousness has been found to predict CWB (Dalal, 2005), Spector et al. (2010) found that the relationship is attenuated substantially when CWB is assessed with a frequency response scale rather than an agreement response scale. 
Table 1: Bivariate Correlations and Descriptive Statistics

$\begin{array}{llllllllllllll}M & S D & 1 & 2 & 3 & 4 & 5 & 6 & 7 & 8 & 9 & 10 & 11 & 12\end{array}$

1. Gender $(0=$ male, $1=$ female $) \quad .55 \quad .50 \quad--$

2. Age (in years) $\quad 30.91 \quad 10.67 \quad .04 \quad--$

3. Hours worked during past week $40.93 \quad 9.00 \quad-.11 * \quad .03 \quad--$

4. Tenure at job (in months) $\quad 47.32 \quad 62.34 \quad-.03 \quad .52 * \quad-.06 \quad--$

5. Job Satisfaction Factor $\quad \begin{array}{lllllllll} & -.04 & .93 & .04 & .05 & -.05 & .08+ & --\end{array}$

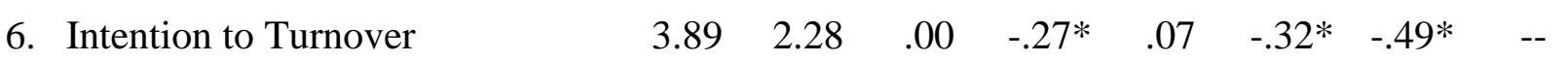

7. Interpersonal Conflict Factor $\quad .10 \quad \begin{array}{llllllllll} & .78 & -.08 & -.16^{*} & .07 & .02 & -.31 * & .17 * & --\end{array}$

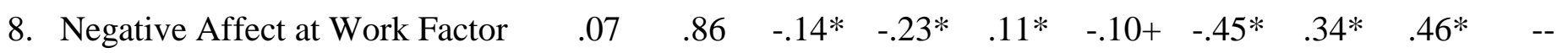

9. Positive Affect at Work Factor $\quad-.03 \quad \begin{array}{llllllllllll} & .94 & -.03 & .13^{*} & .15^{*} & .15^{*} & .60^{*} & -.34^{*} & -.14^{*} & -.17^{*} & --\end{array}$

10. Guilt Proneness Factor $\quad \begin{array}{llllllllllllllll} & -.03 & .86 & .24 * & .27 * & -.06 & .16 * & .06 & -.11 * & -.09+ & -.17 * & .08+ & --\end{array}$

11. CWB Factor $\quad \begin{array}{llllllllllllllll} & .22 & .78 & -.21 * & -.27 * & .06 & -.09+ & -.21 * & .25 * & .53 * & .47 * & -.11 * & -.33 * & --\end{array}$

Note. $N=411$. Means, standard deviations, and bivariate correlations are presented. $+p<.10 ; * p<.05$ 
Table 2: Counterproductive Work Behavior Regression Analysis

\begin{tabular}{|c|c|c|c|c|c|c|c|}
\hline & $B$ & $S E B$ & $\beta$ & $t$ & $p$ & $R^{2}$ & $R^{2}$ \\
\hline Step 1 & & & & & & $.39 *$ & -- \\
\hline Constant & .294 & .046 & & 6.43 & $<.001 *$ & & \\
\hline Gender $(0=$ male, $1=$ female $)$ & -.223 & .062 & -.143 & -3.62 & $<.001 *$ & & \\
\hline Age (in years) & -.010 & .003 & -.131 & -2.75 & $.006^{*}$ & & \\
\hline Hours worked during past week & -.001 & .003 & -.006 & -0.15 & .877 & & \\
\hline Tenure at job (in months) & .000 & .001 & .023 & 0.49 & .624 & & \\
\hline Job Satisfaction Factor & .085 & .049 & .101 & 1.73 & $.084+$ & & \\
\hline Intention to Turnover within a Year & .042 & .016 & .122 & 2.55 & $.011 *$ & & \\
\hline Interpersonal Conflict at Work Factor & .388 & .044 & .391 & 8.76 & $<.001 *$ & & \\
\hline Negative Affect at Work Factor & .220 & .044 & 242 & 4.94 & $<.001^{*}$ & & \\
\hline Positive Affect at Work Factor & -.015 & .042 & -.018 & -0.36 & .721 & & \\
\hline Step 2 & & & & & & $.43^{*}$ & $.04 *$ \\
\hline Constant & .250 & .045 & & 5.53 & $<.001 *$ & & \\
\hline Gender $(0=$ male, $1=$ female $)$ & -.152 & .061 & -.098 & -2.48 & $.014 *$ & & \\
\hline Age (in years) & -.006 & .003 & -.087 & -1.84 & $.066+$ & & \\
\hline Hours worked during past week & -.001 & .003 & -.015 & -.38 & .708 & & \\
\hline Tenure at job (in months) & .000 & .001 & .030 & .65 & .517 & & \\
\hline Job Satisfaction Factor & .076 & .048 & .090 & 1.59 & .112 & & \\
\hline Intention to Turnover & .041 & .016 & .120 & 2.58 & $.010^{*}$ & & \\
\hline Interpersonal Conflict Factor & .389 & .043 & .392 & 9.05 & $<.001 *$ & & \\
\hline Negative Affect at Work Factor & .203 & .043 & .224 & 4.69 & $<.001 *$ & & \\
\hline Positive Affect at Work Factor & -.002 & .041 & -.002 & -.04 & .966 & & \\
\hline Guilt Proneness Factor & -.187 & .037 & -.208 & -5.13 & $<.001 *$ & & \\
\hline
\end{tabular}

Note. $N=411$. Age, hours worked during the past week, tenure at job, and intention to turnover were each mean-centered prior to computing the regression analysis.

$+p<.10 ; * p<.05$ 